\title{
Okun's Law, Asymmetries and Regional Spillovers: Evidence from Virginia Metropolitan Statistical Areas and the District of Columbia *
}

Rui M. Pereira

The College of William and Mary

College of William and Mary

Department of Economics

Working Paper Number 140

First version: June 2013

This version: March 2014

\footnotetext{
*This research was developed with support from Virginia Employment Commission. I would also like to thank Tim Kestner, Peter McHenry, Sarah Stafford and the anonymous referees for their very valuable comments and suggestions.
} 


\author{
COLLEGE OF WILLIAM AND MARY \\ DEPARTMENT OF ECONOMICS \\ WORKING PAPER \# 140 \\ March 2014
}

\title{
Okun's Law, Asymmetries and Regional Spillovers: Evidence from Virginia Metropolitan Statistical Areas and the District of Columbia
}

\begin{abstract}
Abstract: The purpose of this paper is to examine the strength of the relationship between unemployment and GDP, the extent to which this relationship has been stable in Virginia metropolitan statistical areas (MSA) during the Great Recession and to examine the importance of regional spillovers in Okun's law. Our results suggest that regional spillovers are very important in local labor markets and in defining the relationship observed at the national level. The MSA level data further supports asymmetries in Okun's law. The weaker direct relationship between GDP and unemployment at the local level suggests that while federal fiscal and monetary policies to stimulate aggregate demand during periods of economic recovery may be effective, over time, in reducing the unemployment rate, local economic development policies are not effective in achieving the substantial short term reduction in unemployment needed during recovery. The strong business cycle effects observed in the state MSA, relative to the U.S., suggests that countercyclical policies are fundamentally important and should be targeted more generally to exploit regional spillovers.
\end{abstract}

Keywords: Okun's law, the Great Recession, Regional Spillovers, Panel Unit Root Test with Structural Breaks, Panel Spatial Durbin Model.

JEL Classification: C23, E24, E32, J01, R12

Rui M. Pereira

Department of Economics, The College of William and Mary, Williamsburg, USA

PO Box 8795, Williamsburg, VA 23187

rmpereira@wm.edu 


\section{Introduction}

In the wake of the Great Recession, unemployment persists as a significant problem despite moderate growth in economic activity. This apparent disconnect between economic growth and unemployment is particularly concerning, especially in the context of efforts to formulate policies, at both the national and local levels, to promote economic growth to address labor market concerns. The purpose of this paper is to estimate the relationship between the unemployment rate and economic growth, a relationship defined by Okun's Law, in Virginia Metropolitan Statistical Areas (MSA) and the District of Columbia in order to highlight the importance of regional spillovers in determining the local rate of unemployment as well as in reconciling estimates for Okun's law at the national and sub-national levels.

International analyses suggest a weaker relationship between economic growth and unemployment at the sub-national level [see, for example, Apergis and Rezitis (2003), Christopoulos (2004), Villaverde and Maza (2009), Perugini (2009), Kangasharju et al. (2012), Binet and Facchini (2013) and Oberst and Oelgemöller (2013)]. State level estimates of Okun’s law in the U.S. are generally consistent with national estimates, though they tend to show a greater degree of variability [see Blackley (1991), Freeman (2001) and Connaughton and Madsen (2009, 2012)]. Yazgan and Yilmazkuday (2009) find that Okun's coefficient has been converging through time around geographic clusters of U.S. states which underscores the importance of regional forces in local labor markets.

We further examine asymmetries in Okun's law across the business cycle as well as the importance of regional spillovers during periods of contraction. The stability of Okun's law through time has been a source of concern [see Weber (1995), Moosa (1997), Silvapulle et al, (2004), Holmes and Silverstone (2006), Knotek (2007), and Ball et al. (2013)]. This concern is 
particularly apparent in the context of policy efforts to address weak labor market performance since the onset of the Great Recession [see Ball and Koenig (2009) and Owyang and Sekhposyan (2012)] and other jobless recoveries [see Holmes and Silverstone (2006)].

The empirical evidence suggests that the relationship between unemployment and output growth is stronger during periods of economic contraction [see Cuaresma (2003), Silvapulle et al. (2004), Holmes and Silverstone (2006), and Owyang and Sekhposyan (2012)]. We extend these analyses to assess the degree to which asymmetries in Okun's law are a feature of local economies and the extent to which the strength of these effects mirrors that for the U.S.

In this paper, we estimate a Panel Spatial Durbin Model which accounts for spatial dependency and estimate the importance of regional spillovers in local labor markets. Kuscevic (2012) examine Okun's law in U.S. MSA by specifying a Panel Spatial Durbin Model, yet without considering possible asymmetries during the Great Recession. Oberst and Oelgemöller (2013) estimate the relationship between output and unemployment in German regions in this framework but focus primarily on within region effects rather than indirect spillover effects.

Our primary focus is on evaluating the strength of Okun's law at the regional level, during the Great Recession and the importance of regional spillovers in local labor markets. We focus our analysis on Virginia Metropolitan Statistical Areas (MSA) and the District of Columbia. A relatively narrow study region is justified by the fact that the strength of regional integration depends, in part, on proximity. Furthermore, the MSA represent a diverse array of economic conditions, including both rural and urban areas, regions dominated by agriculture, heavy industry and high tech industries, and both large and small regions. These aspects of the study region are in many ways reflective of the diversity present in the U.S. economy and make Virginia MSA an interesting, but not idiosyncratic, case for examining regional spillovers. 


\section{Data and Preliminary Analysis}

\subsection{Data description and scope}

We estimate the relationship between the unemployment rate and the growth rate of GDP using a balanced panel of annual observations on ten Virginia MSA between 2001 and 2011. These are Blacksburg-Christiansburg-Radford, Charlottesville, Danville, Harrisonburg, Lynchburg, Richmond, Roanoke, Virginia Beach-Norfolk-Newport News (VA-NC), Washington-Arlington-Alexandria (DC-VA-MD-WV), and Winchester (VA-WV). These include MSA that are not entirely located in Virginia, particularly the District of Columbia. In addition, we exclude Bristol which does not share a border with any of the remaining MSA (Figure 1). Data on GDP by metropolitan area are from the Bureau of Economic Analysis and data on the unemployment rate are from the Bureau of Labor Statistics.

The Virginia MSA are located in the South Atlantic region of the Eastern Seaboard of the United States. The largest region, in terms of economic output, is Northern Virginia (Washington-Arlington-Alexandria), with $66.3 \%$ of total output, followed by Hampton Roads in Southeastern Virginia (Virginia Beach-Norfolk-Newport News), with 13.1\%, and Richmond, with $10.7 \%$ of total output. The Washington-Arlington-Alexandria MSA is itself roughly the size of the Virginia economy. The smallest MSA, Danville (0.54\%), Winchester (0.82\%) and Blacksburg (0.88\%) represent a very small share of output. These facts suggest a relatively strong concentration of economic activity and are a good indication of the potential importance of spillovers.

The diversity among MSA is also apparent with respect to the industry structure for the local economies. While historically agriculture, and particularly the cultivation of tobacco among other crops, has played a dominant role in the Virginia economy, the state now has very high 
levels of employment and value added in high tech industries and professional and technical services, particularly in Northern Virginia. While agriculture and associated manufacturing activities remain important in Southeastern Virginia, ship building activities and the naval yard in the region are among the largest in the country. In addition, southwestern Virginia has large coal deposits. Furthermore, health industries have been growing across all regions and educational services, due to the presence of several large universities, dominate employment and value added in several MSA. The great diversity between the MSA, both in terms of their size and their industry composition highlight the potential for spillovers stemming from the regional concentration of economic activity and make the Virginia MSA an appealing, but not unusual, case for examining regional spillovers.

Figure 1 Map of Virginia and the Unemployment Rate and Level of Gross State Product (GSP) by MSA during the Great Recession

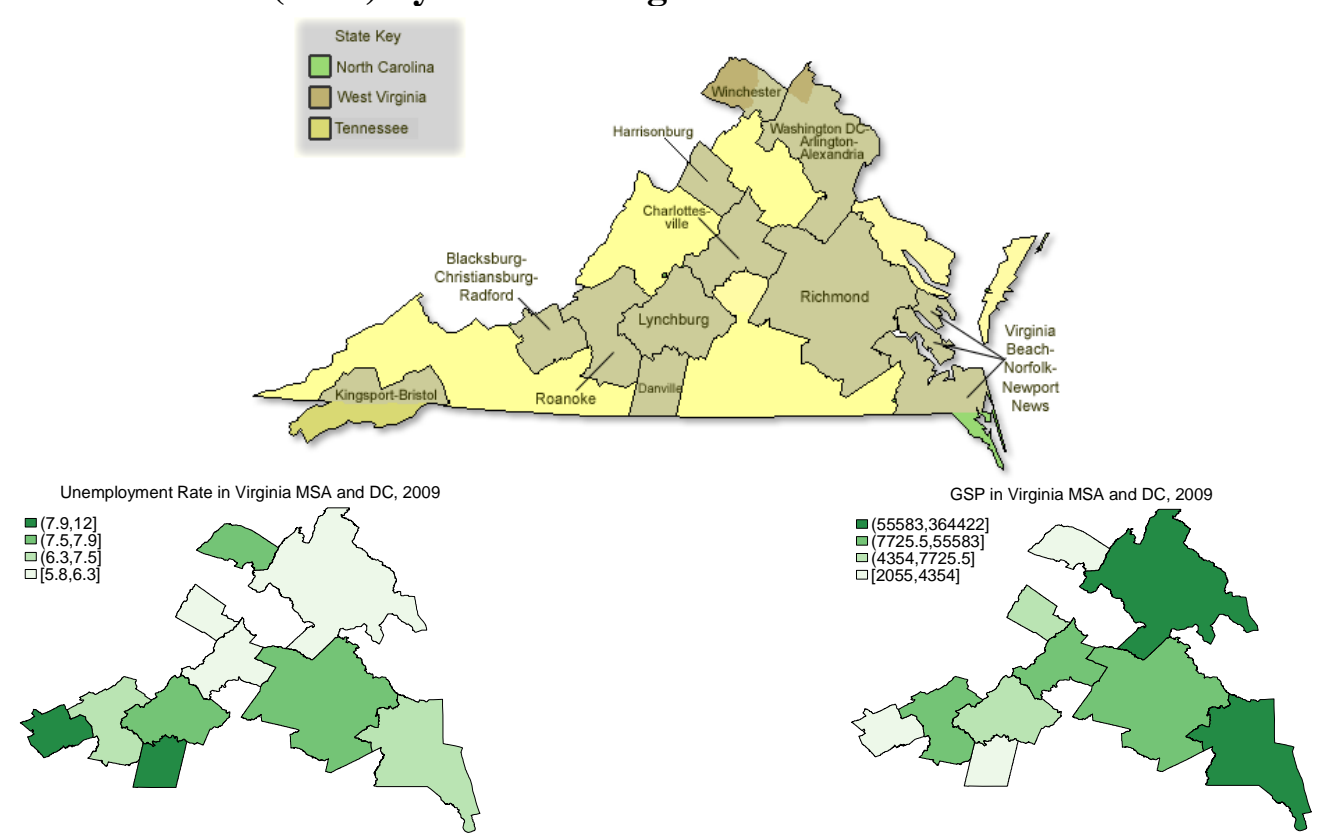

Source: Virginia Employment Commission, Bureau of Labor statistics, Bureau of Economic Analysis and Author's computations. 


\subsection{Preliminary Data Analysis}

We conduct unit root tests for the unemployment rate and GDP. This is important both conceptually and methodologically. First, a potential source of the persistently high unemployment rates observed is hysteresis. If the natural rate of unemployment depends on aggregate demand, that is, if an increase in cyclical unemployment produces a structural increase in the natural rate of unemployment, unemployment hysteresis can contribute towards positive feedbacks that may push up the unemployment rate. Hysteresis in unemployment is defined by the notion that the equilibrium unemployment rate depends on the history of the actual unemployment rate (Blanchard and Summers, 1987). Testing for a linear form of hysteresis in unemployment involves testing for a unit root in the unemployment rate series (Cuestas and GilAlana, 2011). Second, analyses of two I(1) series may lead to spurious correlation among them and the potential need to account for a cointegrating relationship among the variables.

Table 1 presents panel unit root tests results for unemployment and GDP. The Im, Pesaran and Shin (2003) panel unit root test is computed from the individual Augmented Dickey Fuller unit root test statistic for each series. We also conduct a Fisher type test based on the pvalues from the individual Augmented Dickey Fuller unit root test statistics. The number of lags selected is based on the Bayesian Information Criteria. The data are cross-sectionally demeaned to control for cross sectional dependence.

The presence of a structural break reduces the power of the unit root tests (Perron, 1989). Our approach to testing for a unit root in the panel is based on a modification of the Fisher type test which allows for a deterministic break in 2009. We compute p-values for the MSA specific unit root tests with an exogenous break given in 2009 by simulation methods. A permanent break in the levels of the variables is consistent with a one-time break in the growth rates of the series. 
We generate $n=10$ iid $N(0,1)$ random variables and compute the partial sums indicative of a random walk process defined under the null hypothesis. We then estimate $\Delta u r_{t}=\gamma_{1} u r_{t-1}+$ $\gamma_{2} \Delta u r_{t-1}+\alpha_{0}+\gamma_{3} \delta_{09}$, where $\delta_{09}=1$ for years strictly greater than 2008 and obtain the test statistics for the null hypothesis $\gamma_{1}=0$. We repeat this process 10,000 times define the p-value from the sorted vector of replicated statistics. The p-values for the individual series are combined in the test statistic, $-2 \sum_{i=1}^{n} \ln p$ which is distributed as a $\chi_{2 n}^{2}$ random variable. Note that this approach differs from that in Perron (1989) due to the fact that the unemployment rate is not a trending process and we therefore omit the deterministic trend.

We further conduct individual Zivot-Andrews tests for each MSA to allow for endogenously determined break points. For each series, 2009 was endogenously selected as the point of the break. We determine the empirical small sample p-values based on simulation methods to construct a fisher type test statistic for the null of a unit root.

Table 1 Panel Unit Root Tests for Unemployment and GDP

\begin{tabular}{|c|c|c|c|}
\hline & $\begin{array}{c}\text { Unemployment Rate } \\
\text { with a Break } \\
\text { (Zivot Andrews) }\end{array}$ & $\begin{array}{c}\text { Unemployment Rate } \\
\text { with a Break } \\
\text { (Fisher-type test based } \\
\text { on Bai-Perron test) }\end{array}$ & $\begin{array}{c}\text { Growth Rate of } \\
\text { GDP }\end{array}$ \\
\hline Fisher test & $41.0584(0.0037)$ & $108.9636(.0000)$ & $31.0695(.0543)$ \\
\hline \multicolumn{4}{|l|}{ Im, Pesaran and Shin } \\
\hline Average & - & - & -2.166 \\
\hline $\mathrm{W}$ & - & - & $-1.914(.0280)$ \\
\hline Blacksburg-Christiansburg-Radford & $-7.7680(0.1067)$ & $-8.1333(0.0034)$ & $-1.5153(.3914)$ \\
\hline Charlottesville & $-7.2932(0.1256)$ & $-7.3461(0.0042)$ & $-2.0848(.2298)$ \\
\hline Danville & $-8.6601(0.0787)$ & $-9.3535(0.0021)$ & $-2.8713(.1080)$ \\
\hline Harrisonburg & $-6.4762(0.1667)$ & $-7.0669(0.0050)$ & $-1.6519(.3468)$ \\
\hline Lynchburg & $-7.4925(0.1175)$ & $-6.6587(0.0069)$ & $-2.3054(.1847)$ \\
\hline Richmond & $-7.6962(0.1094)$ & $-8.4663(0.0028)$ & $-2.720(.1241)$ \\
\hline Roanoke & $-8.1193(0.0948)$ & $-8.5235(0.0028)$ & $-2.0015(.2495)$ \\
\hline Virginia Beach-Norfolk-Newport News & $-5.7227(0.2240)$ & $-6.3605(0.0086)$ & $-1.5856(.3682)$ \\
\hline Washington-Arlington-Alexandria & $-6.7063(0.1531)$ & $-6.6767(0.0068)$ & $-2.2068(.2031)$ \\
\hline Winchester & $-6.4925(0.1654)$ & $-7.2218(0.0046)$ & $-2.7171(.1244)$ \\
\hline Deterministic & Constant and Trend & Constant, break in 2009 & Constant \\
\hline Lags & 1 & 1 & 1 \\
\hline
\end{tabular}

Source: Author's Calculations; Note: p-values in parentheses for the null of a unit root. 
The results suggest that the unemployment rate is stationary around a break in 2009 and that the growth rate of GDP is stationary around a constant. This indicates that hysteresis in unemployment is not supported in the Virginia MSA.

\section{Methodology}

Okun's law measures the relationship between the unemployment rate and the growth rate of economic activity. This relationship is derived from a production function relating output to labor inputs and defined by the marginal productivity of labor inputs in production. In turn, movements between employment and unemployment are tempered by labor force participation rates (Ball et al, 2013). Okun (1962) estimates this relationship through a regression of the change in the unemployment rate on the growth rate of output. Thirlwall (1969) suggests that this specification may produce results that are biased downwards due to labor hoarding, highlighting

that inversion of the relationship is only valid where the variables are perfectly correlated. The Okun (1962) specification, as followed by Weber (1995) and Cuaresma (2003) among many others, is warranted here due to the policy focus on measures to address the persistently high unemployment rates in recent years through stimulus to aggregate demand.

Our methodological framework is based on the general model

$$
\Delta u_{i t}=\rho \sum_{j} w_{i j} \Delta u_{j t}+\beta g y_{i t}+\theta \sum_{j} w_{i j} g y_{j t}+\varphi \delta_{09} g y_{i t}+a_{i}+v_{i t}
$$

Where $\Delta u_{i t}$ is the change in the unemployment rate, $g y_{i t}$ is the growth rate of GDP, $\delta_{09}$ is an indicator variable for the Great Recession in 2009, $a_{i}$ are MSA specific fixed effects and $v_{i t}$ is the error term. The difference in how the growth rates are denotes reflects differences in the nature of the unemployment rate and GDP. Specifically, the regression is fundamentally expressed in terms of first differences. As is typical, the GDP series is in logarithms. As such, the 
first difference expresses the rate of growth. In contrast, the unemployment rate is already measured as a proportion of the labor force and the log transformation is not employed. Thus, the unemployment rate is measured directly as the change in the unemployment rate, the first difference in the series.

The $\sum_{j} w_{i j} \Delta u_{j t}$ and $\sum_{j} w_{i j} g y_{j t}$ terms correspond to distance weighted sums for the respective macroeconomic variables in other regions. The $w_{i j}$ correspond to elements of the distance weighting matrix, $W$. The distance matrix has zeros along the diagonals and is normalized such that the row sums are equal to one. The weights are computed as the inverse of the distance squared. The distances are obtained as the Euclidean distances from the centroids of the MSA defined by the Census Bureau.

Model (1) collapses to the standard representation of Okun's law in first differences where $\rho=\theta=\varphi=0$, that is, where the regional spillovers and asymmetries during the recession are not significant. The model collapses to an asymmetric representation of Okun's law with $\rho=\theta=0$, absent regional spillovers.

\subsection{Asymmetries in Okun's Law}

This general model provides the framework for evaluating asymmetries in Okun's law as well as the importance of regional spillovers in local labor markets. By imposing the assumption that the regional spillovers are zero, $(\rho=\theta=0)$, we obtain the standard static model with asymmetries. This allows us to evaluate the importance of asymmetries in Okun's law through the parameter $\varphi$ and to examine the influence of omitting the spillovers from the analysis.

$$
\Delta u_{i t}=\beta g y_{i t}+\varphi \delta_{09} g y_{i t}+a_{i}+v_{i t}
$$

The coefficient $\beta$ corresponds to Okun's coefficient during periods of expansion between 2002 and 2008 and 2010, 2011, $\beta+\varphi$ is the corresponding estimate for Okun's coefficient 
during the Great Recession. Time effects for the remaining periods were found to be insignificant. We similarly fail to find evidence of a permanent structural break in Okun's law following the Great Recession.

We focused on latter part of the Great Recession, occurring in 2009, as opposed to examining periods during which the output gap is negative, as is usual in the literature, or the entire recession. The reason for this is that explanations regarding the potential sources for asymmetries in Okun's law, including pessimistic personnel policies, inventory and idle capacity and job matching theories, are rather consistent with a stronger relationship during the onset of the contraction. In 2009, this coincided with substantial cash-flow constraints induced by the absence of liquidity in financial markets that may have contributed towards reductions in payrolls.

The Wooldridge test for autocorrelation in panel data yields a p-value of 0.0002 which suggests that we reject the null of no first-order serial correlation. We therefore consider generalized least squares estimates for the regression model that allow for first order serial correlation as well as iterated generalized least squares estimates with panel $\mathrm{AR}(1)$ serial correlation. The former considers quasi-differenced data based on estimates for the strength of the AR(1) serial correlation. The latter considers MSA specific AR(1) correlated errors. Both are estimators corrected for serial correlation and allow for testing for asymmetries in Okun law by testing the hypothesis that $\varphi=0$. These estimators are asymptotically efficient.

\subsection{Regional spillovers}

Accounting for regional spillovers is important due to important spatial interactions between neighboring cities over their employment cycles (Owyang et al. 2013). The presence of regional spillovers suggests that correlation among the metropolitan areas can induce 
nonspherical disturbances due to serial correlation which, in the presence of spatially lagged dependent variables, will cause OLS estimates to produce inconsistent estimates (Anselin, 1988). To address these issues, we add terms that correspond to the change in the unemployment rate and GDP growth in neighboring areas and estimate the model by maximum likelihood. Estimates are produced using Stata; the data set and do files are available from the author upon request.

The addition of the spatially lagged growth rate of GDP is natural in defining regional spillovers in Okun's law. In well integrated labor markets, the growth rate of GDP in neighboring regions affects the local rate of unemployment. The addition of the spatially lagged unemployment rate is based on the fact that individuals within a particular MSA, who are therefore counted among the unemployed in that region, may not work in the metropolitan area. As unemployment growth here will affect both individual income and GDP growth in neighboring MSA, this can influence the demand for goods and services and therefore the unemployment rate in neighboring areas. In this way spatial autocorrelation becomes important. Failure to account for spillovers of this nature may lead to biased estimates. Asymmetries for the regional spillovers were not found to be statistically significant suggesting that the influence of regional spillovers did not increase significantly during the Great Recession, and are therefore not included in our model.

The regional spillovers generate feedbacks among the MSA that define the effect of a change in the growth rate of output on the unemployment rate. Following LeSage and Pace (2009) and Debarsy et al. (2012), the direct and indirect effects of increases in growth rate of GDP are derived from the equilibrium implied by the spatial difference equation in (1) once the feedbacks among all of the regions have been accounted for. The strength of the ultimate 
resolution of the regional feedbacks depends on proximity and is therefore MSA specific and described by the matrix S.

$$
S(W)=(I-\rho W)^{-1}(\beta I+\theta W)
$$

As such, to define the direct effects of changes in the growth rate of GDP we average the estimated effects over each of the MSA. This measures the change in the unemployment rate in a particular region due to a change in the growth rate of GDP in the region, once the spillovers have been accounted for. The indirect effects measure the average effects, across all MSA, of changes in the growth rate of output in all other regions on unemployment in a particular region. The total effects are then the sum of these two effects and measure the change in unemployment in a region due to a change in the growth rate of output in all regions.

\section{Empirical Results}

\subsection{Okun's Law and Asymmetries}

Table 2 presents the estimates for Okun's Law coefficient using the first difference specification stated in equation (2). The coefficient estimate for the whole sample, resulting from the assumption of an absence in a break in the coefficient, $\varphi=0$, implies that a percentage point increase in GDP growth reduces unemployment by 0.19 percentage points. Our estimate for the Okun coefficient is substantially smaller than the central estimate of 0.3 , a finding that is consistent with the international evidence that the relationship between unemployment and GDP is weaker at the sub-national levels.

Table 2 further presents estimates for asymmetries in Okun's law in Virginia. The results suggest a significant increase in the strength of the relationship between unemployment and GDP

during the recession. During the last decade, for periods of economic growth in VA, the 
estimated coefficient is -0.10 and during the recession the estimated coefficient is -0.67 with 95\% confidence interval around the sum $\beta+\varphi$ given by $[-0.82,-0.51]$. This suggests an additional 0.57 percentage point increase in the unemployment rate for every percentage point loss in GDP during the recession.

The estimated asymmetries show a larger difference between periods of expansion and contraction than that estimated for the U.S. economy. Cuaresma (2003) estimates a coefficient of -0.19 for expansions and -0.44 for contractions. Silvapulle et al. (2004) estimates Okun coefficients of -0.25 and -0.61 with respect to increases and decreases in cyclical output. Owyang and Sekhposyan (2012) estimate a difference of 0.20 during the Great Recession, a difference nearly double that of other recessions. Pereira (2013) estimates Okun's coefficient for the U.S. of -0.42 during periods of expansion and -0.55 during periods of contraction and finds no significant difference between the Great Recession and other recessions in the post-war period with respect to Okun's law.

Table 2 Okun's Law during the Great Recession

\begin{tabular}{rccc}
\hline \hline & $\begin{array}{c}\text { Ordinary Least } \\
\text { Squares }\end{array}$ & $\begin{array}{c}\text { AR(1) Serial } \\
\text { Correlation Model }\end{array}$ & $\begin{array}{c}\text { Iterated Feasible } \\
\text { Generalized Least } \\
\text { Squares with Group } \\
\text { AR(1) Serial } \\
\text { Correlation }\end{array}$ \\
\hline Okun's Law Coefficient & -0.1814 & -0.1716 & -0.1864 \\
\hline Expansions & $(-.2575,-.1054)$ & $(-.2384,-.1048)$ & $(-.2480,-.1248)$ \\
\hline Great Recession & -0.1012 & -0.0907 & -0.0983 \\
& $(-.1471,-.0553)$ & $(-.1513,-.0302)$ & $(-.1569,-.0397)$ \\
\hline \hline
\end{tabular}

95\% Confidence Intervals Given in Parentheses 


\section{$4.2 \quad$ Regional Spillovers}

The preceding analysis highlights that Okun's coefficient is smaller and, more importantly, that the asymmetries in Okun's law during periods of economic contraction are greater at the sub-national level. Table 3 presents the estimated Okun's coefficient and the importance of regional spillovers in determining the local unemployment rate. It is these regional spillovers that tie together estimates for Okun's law at the local and national levels.

The estimate of Okun's law coefficient for the direct effects of output growth on unemployment within the MSA is -0.06 , nearly a third of that found when spillovers are not accounted for. Regional spillovers are fairly large and responsible for more than eighty percent of the total change in the unemployment rate. An increase in output growth in all of the other MSA reduces local unemployment by -0.30 percentage points. The combined effect of local and regional growth on local area unemployment is -0.36 , quite similar to that obtained at the national level.

The asymmetries in the relationship between the change in the unemployment rate and output growth are also driven by regional spillovers. During periods of expansion, local economic growth reduces the unemployment rate by only 0.04 percentage points. During the Great Recession, however, the increase in the unemployment rate was 0.20 percentage points larger, indicating that the unemployment rate increased by 0.24 percentage points for a one percentage point reduction in the local growth rate of economic activity. The influence of growth in neighboring regions, however, is substantial and the asymmetries in the relationship, driven by regional spillovers, are nearly three times as strong as those induced by local effects. 
Table 3 Estimates for the Direct and Indirect Effects from the Spatial Durbin Model

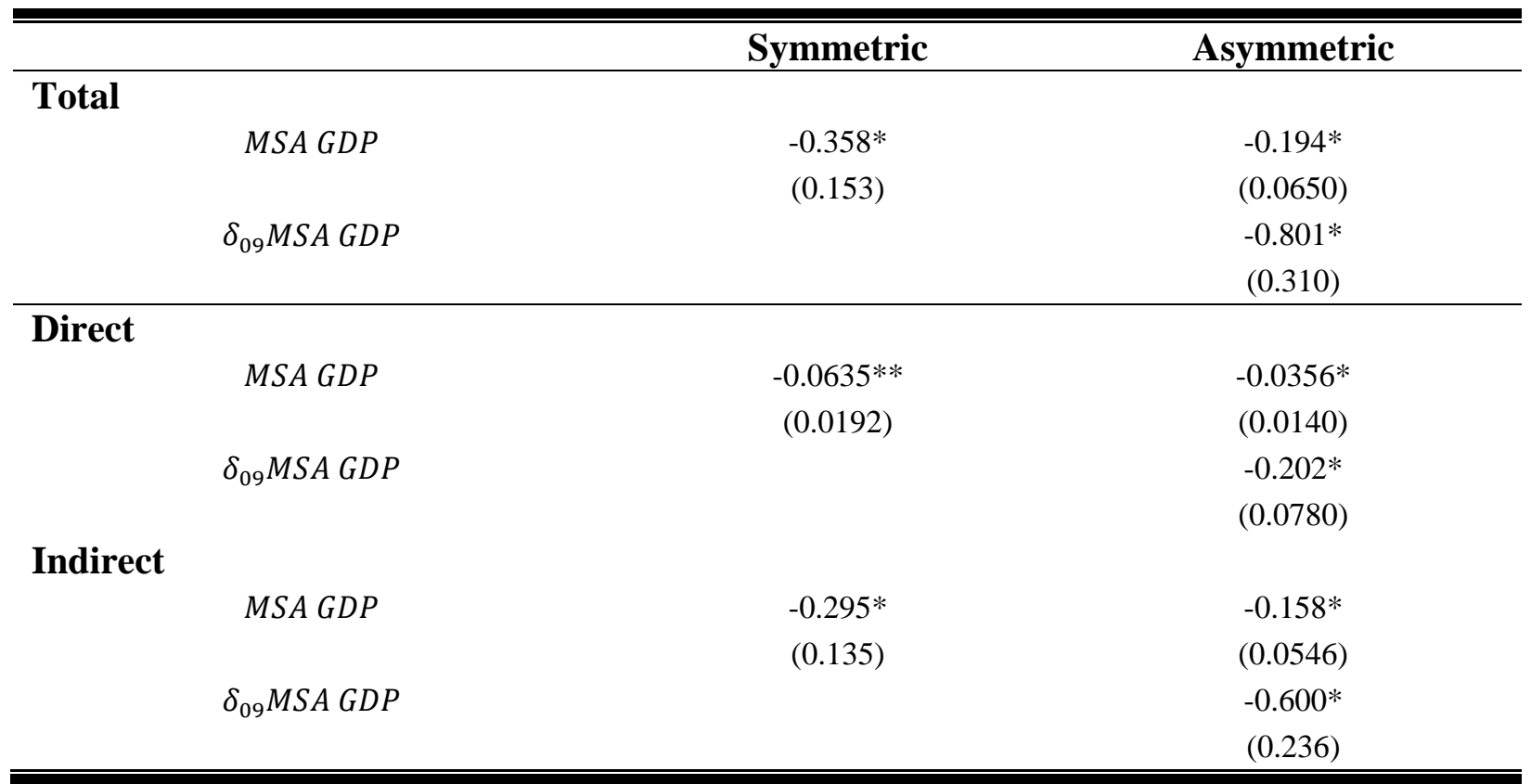

Robust Standard errors in parentheses; ${ }^{* *} \mathrm{p}<0.05,{ }^{*} \mathrm{p}<0.1$

Table 4 Sensitivity Analysis with respect to Distance Weighting Matrix

\begin{tabular}{|c|c|c|c|c|c|}
\hline & $1 / d^{2}$ & $e^{-d}$ & $1 / d$ & Contiguity & Absent D.C. \\
\hline \multicolumn{6}{|l|}{ Total } \\
\hline \multirow[t]{2}{*}{$M S A G D P$} & $-0.194 *$ & $-0.220 *$ & $-0.228^{*}$ & $-0.175^{*}$ & $-0.192 *$ \\
\hline & $(0.0650)$ & $(0.0733)$ & $(0.0747)$ & $(0.0720)$ & $(0.0620)$ \\
\hline \multirow[t]{2}{*}{$\delta_{09} M S A G D P$} & $-0.801^{*}$ & $-0.908^{*}$ & $-1.029 * *$ & -0.635 & -0.779 \\
\hline & $(0.310)$ & $(0.314)$ & $(0.319)$ & $(0.280)$ & $(0.301)$ \\
\hline \multicolumn{6}{|l|}{ Direct } \\
\hline \multirow[t]{2}{*}{$M S A G D P$} & $-0.0356 *$ & $-0.0324^{*}$ & $-0.0305^{*}$ & $-0.0533^{*}$ & -0.0367 \\
\hline & $(0.0140)$ & $(0.0131)$ & $(0.0123)$ & $(0.0174)$ & $(0.0144)$ \\
\hline \multirow[t]{2}{*}{$\delta_{09} M S A G D P$} & $-0.202 *$ & $-0.219 *$ & $-0.249 * *$ & -0.234 & -0.205 \\
\hline & $(0.0780)$ & $(0.0728)$ & $(0.0699)$ & $(0.111)$ & $(0.0781)$ \\
\hline \multicolumn{6}{|l|}{ Indirect } \\
\hline \multirow[t]{2}{*}{$M S A G D P$} & $-0.158^{*}$ & $-0.188 *$ & $-0.198 *$ & -0.122 & $-0.155^{*}$ \\
\hline & $(0.0546)$ & $(0.0638)$ & $(0.0662)$ & $(0.0570)$ & $(0.0522)$ \\
\hline \multirow[t]{2}{*}{$\delta_{09} M S A G D P$} & $-0.600 *$ & $-0.689 *$ & $-0.780 *$ & -0.400 & -0.574 \\
\hline & $(0.236)$ & $(0.246)$ & $(0.254)$ & $(0.172)$ & $(0.227)$ \\
\hline$N$ & 100 & 100 & 100 & 100 & 90 \\
\hline
\end{tabular}

Robust Standard errors in parentheses; ${ }^{* *} \mathrm{p}<0.05,{ }^{*} \mathrm{p}<0.1$ 
To ascertain the relative importance of the direct and spillover effects, tests for equality in these effects were conducted. The p-value for the test of the difference in the point estimates for the direct and indirect effects, against a one-sided alternative, is 0.08 for the symmetric model and 0.06 for the asymmetric model during periods of contraction. Accordingly, the spillovers are statistically larger than the direct effects, accounting for more than half of the total effect of output on unemployment. Note, however, that even the rejection of the null would be consistent with sizable spillover effects as it suggests that they would be statistically of the same magnitude as the direct effects.

The total effect of an increase in the growth rate of economic activity in all regions in a single MSA mirrors those effects found for Okun's law at the national level. During periods of expansion a one percentage point increase in the growth rate of economic activity reduces the unemployment rate by 0.19 percentage points. In 2009, during the Great Recession, a one percentage point reduction in the growth rate of economic activity across all Virginia MSA increased the unemployment rate, on average, by nearly a percentage point. The asymmetries are naturally very large although the national estimates are within the margin of error for the estimated effect. The importance of regional spillovers reflects, and can be explained in part by, the concentration of economic activity in the Washington-Arlington-Alexandria (DC-VA-MDWV), Virginia Beach-Norfolk-Newport News (VA-NC) and Richmond coupled with the relatively small share of employment and output in the remaining MSA.

\subsection{Sensitivity Analysis}

Table 4 presents a sensitivity analysis for the importance of regional spillovers and asymmetries in Okun's law in Virginia. We consider three alternative distance weighting matrices. While the results are generally consistent across the various distance matrices, these 
results highlight the importance of distance in defining regional spillovers. Distance weighting matrices that impose a smaller penalty for distance tend to provide for larger asymmetries and larger regional spillovers.

Furthermore, given the size and importance of the Washington-Arlington-Alexandria MSA, which encompasses the District of Columbia and Northern Virginia, we conduct a sensitivity analysis which excludes this region. The exclusion of this MSA from the analysis has a very small effect on our estimates of the importance of asymmetries and regional spillovers in Okun's Law. Naturally, the reduction in the number of observations due to the exclusion of this region increases the variance in our estimators.

The general picture that emerges from this sensitivity analysis is that the distance between the regions is important in defining the strength of regional spillovers and that our central modeling assumptions represents a somewhat conservative assessment of the importance of regional spillovers.

\section{Conclusions and Policy Implications}

The purpose of this paper is to examine the strength of the relationship between unemployment and GDP at the MSA level, to determine the extent to which this relationship has been stable in Virginia through the Great Recession and to examine the importance of regional spillovers in Okun's law. Our results highlight the importance of regional spillovers in well integrated product and labor markets and strong asymmetries in Okun's law across the business cycle. The fairly substantial spillovers among regions tie together the disparities observed in estimates for Okun's coefficient at the national and sub-national levels. Failure to account for 
these regional spillovers leads to results that suggest a substantially weaker relationship between unemployment and GDP in Virginia than that estimated for the U.S. economy.

These results have several important implications for policy. In particular, although we focus on the Virginia/Washington D.C. area, the results are far from parochial. First, the weaker relationship between GDP and unemployment at the local level suggests that while federal fiscal and monetary policies to stimulate aggregate demand during periods of economic recovery may be effective, over time, in reducing the unemployment rate, local economic development policies are not effective in achieving the substantial short term reduction in unemployment needed during recovery. These results are consistent with those found in the literature regarding the effectiveness of state and local economic stabilization policies. In general, the effects of local policies are weak and stabilization policies are better addressed at the federal level [see, for example, Oates (1972), and Carlino and Inman (2013)]. This is particularly important due to the large role that regional spillovers play in local labor markets.

Second, the asymmetries in Okun's law across the business cycle have implications for both the nature and the timing of policies to improve labor market outcomes. The presence of asymmetries in Okun's law suggests that, during a weak recovery, the increase in economic growth required to recover the jobs lost during the recession may be substantial. The magnitudes involved are especially aggravated by the presence of more substantial asymmetries at the regional level, relative to those estimated for the U.S. The stronger business cycle effects observed in a state like Virginia, relative to the U.S., suggests that countercyclical policies are fundamentally important and should be targeted more generally to exploit regional spillovers. That is, early action to mitigate the drop in aggregate demand will have a more pronounced effect on unemployment than policies designed during the recovery to accelerate job growth. 


\section{References:}

Anselin, L. 1988. Spatial Econometrics: Methods and Models. (Dorddrecht: Kluwer Academic Publishers).

Apergis, N., Rezitis, A., 2003. An examination of Okun's law: evidence from regional areas in Greece. Applied Economics 35(10), 1147-1151.

Ball, N., Koenig, E., 2009. Recent unemployment increases break the law. Federal Reserve Bank of Dallas National Economic Update, June 29. http://dallasfed.org/research/updateus/2009/0904.cfm (accessed April 5, 2012).

Ball, L., Leigh, D., Loungani, P., 2013. Okun's Law: Fit at Fifty?, NBER Working Papers 18668, National Bureau of Economic Research, Inc.

Binet, M., Facchini, F.. 2013. Okun's law in the french regions: a cross-regional comparison. Economics Bulletin 33(1), 420-433.

Blackley, P., 1991. The Measurement and Determination of Okun's Law: Evidence from State Economies. Journal of Macroeconomics 13(4), 641-656.

Blanchard, O., Summers, L., 1987. Hysteresis in unemployment. European Economic Review 31(1-2), 288-295.

Carlino, G., Inman, R., 2013. Local Deficits and Local Jobs: Can U.S. States Stabilize Their Own Economies? NBER Working Paper No. 18930, National Bureau of Economic Research, Inc.

Christopoulos, D. 2004. The Relationship Between Output and Unemployment: Evidence from Greek Regions. Papers in Regional Science 83(3), 611-620.

Connaughton, J., Madsen, R., 2009. Regional implications of the 2001 recession. The Annals of Regional Science, 43(2), 491-507.

Connaughton, J., Madsen, R., 2012. U.S. State and Regional Economic Impact of the 2008/2009 Recession. Journal of Regional Analysis and Policy, 42(3).

Cuaresma, J. 2003. Okun's Law Revisited. Oxford Bulletin of Economics and Statistics 65(4), 439-451.

Cuestas J., Gil-Alana, L., 2011. “Unemployment Hysteresis, Structural Changes, Non-Linearities and Fractional Integration in European Transition Economies”, Sheffield Economic Research Paper Series, University of Sheffield, United Kingdom

Debarsy, N., Ertur, C., LeSage, J., 2012. Interpreting dynamic space-time panel data models. Statistical Methodology 9(1-2), 158-171.

Freeman, D., 2001. Panel tests of Okun's Law for Ten Industrial Countries. Economic Inquiry 39(4), 511-523.

Holmes, M., Silverstone, B., 2006. Okun's law, asymmetries and jobless recoveries in the United States: A Markov-switching approach. Economics Letters 92(2), 293-299. 
Im, K., Pesaran, M., Shin, Y., 2003. Testing for unit roots in heterogeneous panels. Journal of Econometrics 115, 53-74.

Kangasharju, A., Tavera, C., Nijkamp, P., 2012. Regional Growth and Unemployment: The Validity of Okun's Law for the Finnish Regions. Spatial Economic Analysis 7(3), 381395.

Knotek, E., 2007. How Useful is Okun's Law? Federal Reserve Bank of Kansas City, Economic Review. Fourth Quarter, 2007.

Kuscevic, C., 2012. Okun’s Law and Urban Spillovers. Banco Central de Bolivia, Encuentro de Economistas de Bolivia. http://www.bcb.gob.bo/eeb/sites/default/files/paralelas5eeb/viernes/Macroeconomia\%20 B/Casto\%20Montero.pdf

LeSage J., Pace, R., 2009. Introduction to spatial econometrics. CRC Press Taylor \& Francis Group, Boca Raton

Moosa, I., 1997. A Cross-Country Comparison of Okun's Coefficient. Journal of Comparative Economics 24(3), 335-356.

Moretti, E., 2011. Local Labor Markets, in O. Ashenfelter \& D. Card (ed.), 2011. Handbook of Labor Economics, Elsevier, edition 1, volume 4, number 5.

Oates, W., 1972. Fiscal Federalism. Harcourt Brace Jovanovich, New York.

Oberst, C., Oelgemöller, J., 2013. Economic Growth and Regional Labor Market Development in German Regions: Okun's Law in a Spatial Context, FCN Working Papers 5/2013, E.ON Energy Research Center, Future Energy Consumer Needs and Behavior (FCN).

Okun, A. 1962. Potential GNP: Its Measurement and Significance. Proceedings of the Business and Economics Statistics Section of the American Statistical Association: 98-104.

Owyang, M., Sekhposyan, T., 2012. Okun's Law over the Business Cycle: Was the Great Recession All That Different? Federal Reserve Bank of St. Louis Review, September/October 2012, 94(5), 399-418.

Owyang, M., M., Piger, J., Wall H., 2013. Discordant city employment cycles. Regional Science and Urban Economics 43, 2, 367-384.

Pereira, R., 2013. Okun's Law across the Business Cycle and during the Great Recession: A Markov Switching Analysis. The College of William and Mary Working Paper Series.

Perron, P., 1989. The Great Crash, the Oil Price Shock, and the Unit Root Hypothesis. Econometrica 57(6), 1361-1401.

Perugini, C., 2009. Employment Intensity Of Growth In Italy. A Note Using Regional Data. Regional and Sectoral Economic Studies 9(1).

Silvapulle, P., Moosa, I., Silvapulle, M., 2004. Asymmetry in Okun's law. Canadian Journal of Economics 37(2), 353-374. 
Thirlwall, A., 1969. Okun's Law and the Natural Rate of Growth. The Southern Economic Journal 36, 87-89

Villaverde, J., Maza, A., 2009. The robustness of Okun's law in Spain, 1980-2004: Regional evidence. Journal of Policy Modeling 31(2), 289-297.

Weber, C. 1995. Cyclical Output, Cyclical Unemployment and Okun's Coefficient: A New Approach. Journal of Applied Econometrics 10, 433-445.

Yazgan M., Yilmazkuday, H., 2009. Okun's convergence within the US. Letters in Spatial and Resource Sciences 2(2), 109-122. 